\title{
1-Methylimidazolium trifluoroacetate [Hmim]Tfa: Mild and efficient Brønsted acidic ionic liquid for Hantzsch reaction under microwave irradiation
}

\author{
JEMIN R AVALANI, DEVJI S PATEL and DIPAK K RAVAL* \\ Department of Chemistry, Sardar Patel University, Vallabh Vidyanagar 388 120, India \\ e-mail: dipanalka@yahoo.com
}

MS received 25 February 2012; revised 17 April 2012; accepted 30 April 2012

\begin{abstract}
One pot synthesis of 1,4-dihydropyridine derivatives was achieved via condensation of various $\beta$-ketoesters with aromatic/aliphatic aldehydes and ammonium acetate. The reaction was catalysed by a stable and reusable Brønsted acidic ionic liquid (IL), 1-methyl-imidazolium trifluoroacetate ([Hmim]Tfa), under microwave (MW) irradiation. The synergistic combination of MW with IL can potentially go a long way to meet the increasing demand for chemical processes. This homogeneous catalytic procedure is simple and efficient. The catalyst can be reused at least four times with almost complete retention in its activity.
\end{abstract}

Keywords. 1,4-Dihydropyridine; Hantzsch synthesis; [Hmim]Tfa; homogeneous catalyst; microwave; multicomponent reaction.

\section{Introduction}

Current conventional methods of organic synthesis are orders of magnitude too slow to satisfy the everincreasing demand for generation of organic compounds. ${ }^{1}$ The efficiency of microwave (MW) heating has resulted in remarkable reductions in reaction times (from days and hours to minutes and seconds). The time saved by using a MW heating approach is potentially important in traditional organic chemistry and assembly of heterocyclic systems. ${ }^{2}$ Not surprisingly, these features have also recently attracted interest of the drug discovery field and medicinal chemistry communities. ${ }^{3}$

In recent years, ionic liquids (ILs) have attracted immense interest and been successfully used in a variety of catalytic reactions as dual solvents-catalysts ${ }^{4}$ due to their relatively low viscosities, low vapour pressure, and high thermal and chemical stability. ${ }^{5}$ Brønsted acidic ionic liquids consist of desired characteristics of solid acids and mineral liquid acids and are designed to replace customary mineral acids like $\mathrm{HCl}, \mathrm{H}_{2} \mathrm{SO}_{4}$ and $\mathrm{HNO}_{3} \cdot{ }^{6}$

Heterocyclic rings containing nitrogen atoms are abundant in nature and of great importance to life because their structural subunit exists in many bioactive nuclei. ${ }^{7}$ 1,4-DHPs represent an important class of biologically active molecules, several of which have found use in the treatment of cardiovascular disease. ${ }^{8,9} 1,4-$ DHPs are analogues of NADH coenzymes ${ }^{10,11}$ and an important class of drugs which are potent blockers of calcium $\left(\mathrm{Ca}^{2+}\right)$ currents. ${ }^{12}$ Hence, the development of new methods that lead to multisubstituted 1,4-DHPs via an efficient and convenient procedure are of great interest for pharmaceutical researchers.

More than a century ago, Hantzsch ${ }^{13}$ developed an efficient method for the synthesis of 1,4-DHPs. The classical method involves a one-pot condensation of an aldehyde with $\beta$-ketoesters and ammonia refluxing either in acetic acid or in alcohol for a longer time, ${ }^{14}$ Up till now, numerous literature exist describing various attempts to improve the Hantzsch reaction using alternative catalyst and greener methods. ${ }^{15-24}$ Almost all of the new methodologies of organic reactions have attempted to maximize reaction conversion and minimize reaction time. We have already demonstrated the efficient role of ionic liquids as dual solvent-catalysts in Biginelli reaction. ${ }^{25,26}$ In the present study, we report 1-methyl-imidazolium trifluoroacetate ([Hmim]Tfa) as an effective and reusable catalyst for Hantzsch pyridine synthesis (scheme 1).

*For correspondence 

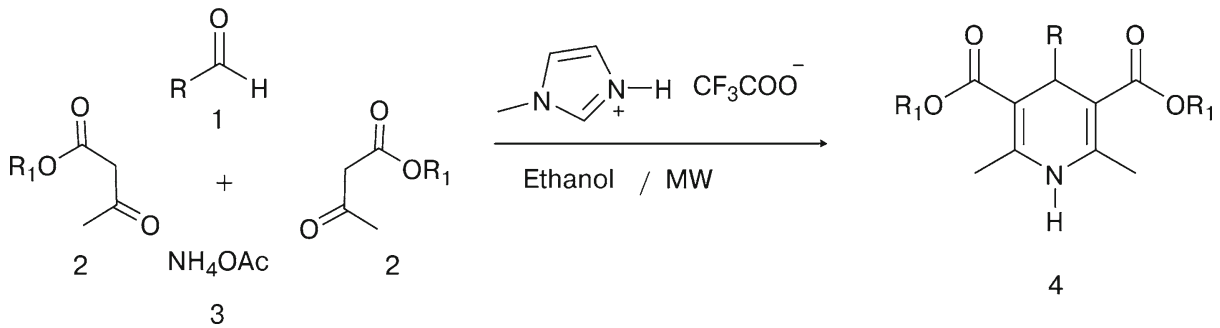

Scheme 1. General synthetic pathway for the synthesis of 1,4-dihydropyridines (1,4-DHPs).

\section{Experimental}

\subsection{General}

All chemicals were of research grade and were used as obtained. The reactions were carried out by using 700 Watt CATA-R scientific microwave system. Melting points were measured in open capillaries and are uncorrected. TLC was performed on Silica Gel $60 \mathrm{~F}_{254}$ pre-coated plates (Merck). IR spectra were recorded on a FT IR Perkin Elmer Spectrum 100 spectrometer, mass spectra on a Shimadzu LCMS 2010 spectrometer, and elemental analysis on Perkin Elmer PE 2400 elemental analyzer. ${ }^{1} \mathrm{H}$ NMR and ${ }^{13} \mathrm{C}$ NMR spectra were recorded on Bruker Avance $400 \mathrm{MHz}$ instrument with TMS as an internal standard. The IL [Hmim]Tfa was prepared according to the procedure reported in literature. ${ }^{27}$

\subsection{Procedure for the synthesis of 1,4-DHPs}

A mixture of aldehyde $\mathbf{1}$ (1 mmol), 1,3dicarbonylcompound 2 (2.1 mmol), ammonium acetate 3 (3 mmol), ethanol $(1 \mathrm{ml})$ and [Hmim]Tfa $(20 \mathrm{~mol} \%)$ were taken in a round bottom flask containing a teflon-coated magnetic stirrer bar. It was subjected to microwave irradiation at power level 7 (455 watt) for an appropriate time shown in table 3 . The completion of reaction was monitored by TLC. The reaction mixture was treated with cold water, extracted with diethyl ether and dried over anhydrous $\mathrm{Na}_{2} \mathrm{SO}_{4}$. It was then concentrated under reduced pressure to leave the crude product which was crystallized in ethanol. The compounds have been identified by comparison of spectral data and $\mathrm{mp}$ with those reported elsewhere.

\subsection{Spectral data for selected compounds}

2.3a Dimethyl 2,6-dimethyl-4-(4-nitrophenyl)-1,4dihydropyridine-3,5-dicarboxylate (4d): Anal.Calcd. For $\mathrm{C}_{17} \mathrm{H}_{18} \mathrm{~N}_{2} \mathrm{O}_{6}$ : C,58.96; H,5.24; N,8.09. Found: C, 59.30; H, 5.10; N, 7.84. IR (KBr) $\mathrm{cm}^{-1}: 3304(-\mathrm{NH}$ stretching of amine), 2949 (-CH stretching), 1696, 1645 (respectively due to $\mathrm{C}=\mathrm{O}$ and $\mathrm{C}=\mathrm{C}$ stretching of conjugate ester), 1487, 1342, $1215 ;{ }^{1} \mathrm{H} \mathrm{NMR}(400 \mathrm{MHz}$, $\left.\mathrm{CDCl}_{3}\right): \delta 2.37\left(\mathrm{~s}, 6 \mathrm{H},-\mathrm{CH}_{3}\right), 3.66\left(\mathrm{~s}, 6 \mathrm{H},-\mathrm{OCH}_{3}\right), 5.12$ (s, 1H,aryl $-\mathrm{CH}$ of $\mathrm{C} 4), 5.86(\mathrm{~s}, 1 \mathrm{H},-\mathrm{NH}), 7.45$ (d, $J=8.8 \mathrm{~Hz}, 2 \mathrm{H}, \mathrm{Ar}-\mathrm{H}), 8.10(\mathrm{~d}, J=8.8 \mathrm{~Hz}, 2 \mathrm{H}, \mathrm{Ar}-\mathrm{H})$; ${ }^{13} \mathrm{C}$ NMR $\left(100 \mathrm{MHz}, \mathrm{CDCl}_{3}\right): \delta 19.63\left(-\mathrm{CH}_{3}\right), 39.87$, 51.14, 103.02, 123.45, 128.60, 144.91, 146.43, 154.75, $167.47(\mathrm{C}=\mathrm{O})$. ESI-MS: $m / z: 346.9(\mathrm{M}+\mathrm{H})^{+}$

2.3b Diethyl 4-(furan-2-yl)-2,6-dimethyl-1,4-dihydropyridine-3,5-dicarboxylate (4k): Anal.Calcd. For $\mathrm{C}_{17} \mathrm{H}_{21} \mathrm{NO}_{5}$ : C, 63.94; H, 6.63; N, 4.39. Found: C, 63.72; H, 7.01; N, 4.11. IR (KBr) $\mathrm{cm}^{-1}: 3348(-\mathrm{NH}$ stretching of amine), 2985 (-CH stretching), 1692, 1649 (respectively due to $\mathrm{C}=\mathrm{O}$ and $\mathrm{C}=\mathrm{C}$ stretching of conjugate ester), 1486, $1209 .{ }^{1} \mathrm{H}$ NMR $(400 \mathrm{MHz}$, $\left.\mathrm{CDCl}_{3}\right): \delta 1.28\left(\mathrm{t}, J=7.2 \mathrm{~Hz}, 6 \mathrm{H},-\mathrm{CH}_{2} \mathrm{CH}_{3}\right), 2.34(\mathrm{~s}$, $\left.6 \mathrm{H},-\mathrm{CH}_{3}\right), 4.18\left(\mathrm{~m}, 4 \mathrm{H},-\mathrm{CH}_{2} \mathrm{CH}_{3}\right), 5.22(\mathrm{~s}, 1 \mathrm{H}$, aryl $\mathrm{CH}$ of C4), $5.84(\mathrm{~s}, 1 \mathrm{H},-\mathrm{NH}), 5.95(\mathrm{~d}, J=3.2 \mathrm{~Hz}, 1 \mathrm{H}$, Ar-H), 6.23 (dd, $J=2.8,2 \mathrm{~Hz}, 1 \mathrm{H}, \mathrm{Ar}-\mathrm{H}), 7.23$ (s, $1 \mathrm{H}$, $\mathrm{Ar}-\mathrm{H}) ;{ }^{13} \mathrm{C}$ NMR $\left(100 \mathrm{MHz}, \mathrm{CDCl}_{3}\right): \delta 14.32,19.51$, 33.43, 59.80, 100.78, 104.43, 109.98, 140.84, 145.02, 158.70, $167.46(\mathrm{C}=\mathrm{O})$. ESI-MS: $m / z: 319.8(\mathrm{M}+\mathrm{H})^{+}$

2.3c Diisopropyl 4-(furan-2-yl)-2,6-dimethyl-1,4-dihydropyridine-3,5-dicarboxylate (41): Anal.Calcd. For $\mathrm{C}_{19} \mathrm{H}_{25} \mathrm{NO}_{5}$ : C, 65.69; H, 7.25; N, 4.03. Found: C, 65.86; H, 7.57; N, 3.79. IR (KBr) $\mathrm{cm}^{-1}: 3347(-\mathrm{NH}$ stretching of amine), 2978 (-CH stretching), 1696, 1649 (respectively due to $\mathrm{C}=\mathrm{O}$ and $\mathrm{C}=\mathrm{C}$ stretching of conjugate ester), 1483, 1208. ${ }^{1} \mathrm{H}$ NMR $(400 \mathrm{MHz}$, $\left.\mathrm{CDCl}_{3}\right): \delta 1.22\left(\mathrm{dd}, J=6,0.8 \mathrm{~Hz}, 6 \mathrm{H},-\mathrm{CH}_{3}\right), 1.28(\mathrm{dd}$, $J=6.4,1.2 \mathrm{~Hz}, 6 \mathrm{H}), 2.33(\mathrm{~s}, 6 \mathrm{H}), 5.05(\mathrm{~m}, 2 \mathrm{H}), 5.2(\mathrm{~s}$, 1H), $5.76(\mathrm{~s}, 1 \mathrm{H}), 5.95(\mathrm{~s}, 1 \mathrm{H}), 6.22(\mathrm{~m}, 1 \mathrm{H}), 7.22(\mathrm{~s}, 1 \mathrm{H})$; ${ }^{13} \mathrm{C}$ NMR $\left(100 \mathrm{MHz}, \mathrm{CDCl}_{3}\right): \delta 19.52,22.07,33.59$, 67.02, 101.15, 104.47, 109.92, 140.67, 144.54, 158.92, $167.01 \mathrm{C}=\mathrm{O} . \mathrm{ESI}-\mathrm{MS}: m / z: 347.9(\mathrm{M}+\mathrm{H})^{+}$ 


\section{Results and discussion}

Our first objective was to develop a set of working conditions for the microwave mediated process. Initially we optimized the reaction conditions with respect to microwave power $(P)$. The reaction of $p$-nitro benzaldehyde, methyl acetoacetate and ammonium acetate was performed as the model reaction in the presence of catalytic amount of [Hmim]Tfa in ethanol as cosolvent. The results are given in table 1 .

It could be observed that with increase in microwave power from $280 \mathrm{~W}$ to $700 \mathrm{~W}$, the yield of $\mathbf{4 d}$ is linearly increased from $55 \%$ to $93 \%$. At higher power level $(700 \mathrm{~W})$ reaction completed in $3 \mathrm{~min}$ but resulted in moderate yield. The optimized microwave power and the irradiation time were $455 \mathrm{~W}$ and $2 \mathrm{~min}$, respectively.

The model reaction was also screened to know the effect of a range of different solvents as shown in table 2. It was noted that in ethanol, the yield of desired product $\mathbf{4 d}$ was achieved exclusively up to $93 \%$ (table 2 , entry 5). When we carried out the reaction in other solvent such as acetonitrile, DMF, THF and 1, 4-dioxane the yield of $\mathbf{4 d}$ was $80,63,70$ and $75 \%$ respectively.

Above experimental results encouraged us to extend the scope of reaction condition to apply on a range of variously substituted aldehydes (table 3). Both electron-deficient and electron-rich aldehydes were well-tolerated. The reaction of heteroaromatic aldehydes and formaldehyde proceeded in very short reaction time (entry $4 \mathrm{j}-40$ ). Ethyl acetoacetate and isopropyl acetoacetate were also employed for the Hantzsch reaction in place of methyl acetoacetate to afford appropriate 1,4-DHPs in good yield. All the reactions were completed in 1-4 min. Increase in the equivalent of IL did not improve the conversion, use of just $20 \mathrm{~mol} \%$ IL is found to be sufficient to accelerate the reaction forward.

Table 1. Effect of the microwave power and the irradiation time on the model reaction $(4 \mathrm{~d})^{\mathrm{a}}$.

\begin{tabular}{lccc}
\hline Entry & Time $(\min )^{\mathrm{b}}$ & $P($ watt $)$ & ${\text { Yield }(\%)^{\mathrm{c}}}^{\mathrm{c}}$ \\
\hline 1 & 8 & 280 & 55 \\
2 & 6 & 350 & 65 \\
3 & 5 & 420 & 80 \\
4 & 2 & 455 & 93 \\
5 & 3 & 490 & 89 \\
6 & 3 & 700 & 80 \\
\hline
\end{tabular}

aReaction conditions: Aldehyde (1 mmol), $\beta$-ketoester (2.1 mmol), ammonium acetate $(3 \mathrm{mmol})$, ethanol $(1 \mathrm{ml})$, [Hmim]Tfa $20 \mathrm{~mol} \%$; ${ }^{b}$ Reaction progress was monitored by TLC; ${ }^{\mathrm{c}}$ All yields refer to isolated yield
Table 2. Effect of solvent on model reaction (4d) .

\begin{tabular}{lccc}
\hline Entry & Solvent & Time $(\min )^{\mathrm{c}}$ & Yield $(\%)^{\mathrm{b}}$ \\
\hline 1 & Acetonitrile & 3 & 80 \\
2 & DMF & 2 & 63 \\
3 & THF & 4 & 70 \\
4 & 1,4-Dioxane & 3 & 75 \\
5 & Ethanol & 2 & 93 \\
\hline
\end{tabular}

aReaction conditions: Aldehyde (1 mmol), $\beta$-ketoester (2.1 mmol), ammonium acetate $(3 \mathrm{mmol})$, [Hmim]Tfa $20 \mathrm{~mol} \%, P=455 \mathrm{~W}$; ${ }^{\mathrm{b}}$ Isolated yield; ${ }^{\mathrm{c}}$ Reaction progress was monitored by TLC

The IL, [Hmim]Tfa may promote this reaction by virtue of its inherent Brønsted acidity conferred by the most acidic $-\mathrm{N}-\mathrm{H}$ hydrogen [chemical shift $\delta 10.93$ ]. This makes the IL capable of bonding with the carbonyl oxygen of aldehydes and $\beta$-ketoesters increasing the reactivity of the parent carbonyl compounds. Crowhurts et al. demonstrated that imidazolium ILs are able to act as strong hydrogen bond acids as well as bases at the same time. ${ }^{28}$ Many current studies have established that hydrogen bonding can occur between the reactant and the cationic or anionic components of ILs. ${ }^{29,30}$ Based on this, the following mechanistic pathway has been postulated (scheme 2).

The IR spectrum of the product showed strong band around $3300-3350 \mathrm{~cm}^{-1}$ due to $\mathrm{N}-\mathrm{H}$ stretching and bands around 1645 and $1696 \mathrm{~cm}^{-1}$ respectively due to $\mathrm{C}=\mathrm{C}$ and $\mathrm{C}=\mathrm{O}$ stretching of conjugated ester moieties where as the aromatic $\mathrm{C}=\mathrm{C}$ was found at $1483-1487 \mathrm{~cm}^{-1}$. In the ${ }^{1} \mathrm{H}$ NMR spectrum, singlet was observed around $\delta$ 5.12-5.22 due to aryl-CH moiety of the $\mathrm{C}-4$ of the dihydropyridine skeleton. In case of all the products described in table 3, broad singlet appeared around $\delta 5.75-5.86$ confirming the presence of $\mathrm{N}-\mathrm{H}$ group. In all the aforesaid cases, six-proton singlet was observed due to olefinic$\mathrm{CH}_{3}$ around $\delta$ 2.32-2.37 corroborated with the 1,4DHPs skeleton. In the ${ }^{13} \mathrm{C}$ NMR spectra, peak around $\delta$ 167.00-167.50 was due to carbonyl carbon of ester moiety.

The recovery and reusability of the ionic liquid was investigated. After completion of the reaction, ice cold water was added to the reaction mixture and product was extracted with diethyl ether. The aqueous layer consisting the acidic IL, was recovered after removal of water under reduced pressure and was reused for subsequent reactions. It showed the same activity as that of the fresh catalyst without any loss of activity in terms of yield and purity. The ionic liquid was recycled and reused in the same reaction for at least 
Table 3. Synthesis of 1,4-dihydropyridines in the presence of $20 \mathrm{~mol} \%$ [Hmim]Tfa.

\begin{tabular}{|c|c|c|c|c|c|c|}
\hline Entry & $\mathrm{R}$ & $\mathrm{R}^{1}$ & Time (Min) & Yield (\%) & M.P. $\left({ }^{\circ} \mathrm{C}\right)$ (observed) & M.P. $\left({ }^{\circ} \mathrm{C}\right)$ (reported) \\
\hline $4 a$ & $\mathrm{C}_{6} \mathrm{H}_{5}$ & $\mathrm{CH}_{3}$ & 3 & 90 & 194 & $195-197^{31}$ \\
\hline $4 \mathrm{~b}$ & $\mathrm{C}_{6} \mathrm{H}_{5}$ & $\mathrm{CH}_{3} \mathrm{CH}_{2}$ & 3 & 92 & $156-158$ & $158-160^{32}$ \\
\hline $4 c$ & $4-\mathrm{ClC}_{6} \mathrm{H}_{4}$ & $\mathrm{CH}_{3}$ & 2 & 86 & 198 & $196-197^{33}$ \\
\hline $4 d$ & $4-\mathrm{O}_{2} \mathrm{NC}_{6} \mathrm{H}_{4}$ & $\mathrm{CH}_{3}$ & 2 & 93 & 196-198 & $195-196^{34}$ \\
\hline $4 \mathrm{e}$ & $4-\mathrm{FC}_{6} \mathrm{H}_{5}$ & $\mathrm{CH}_{3}$ & 3 & 82 & 170 & $170-171^{37}$ \\
\hline $4 \mathrm{f}$ & $3-\mathrm{O}_{2} \mathrm{NC}_{6} \mathrm{H}_{4}$ & $\mathrm{CH}_{3} \mathrm{CH}_{2}$ & 3 & 86 & 162 & $160-162^{32}$ \\
\hline $4 \mathrm{~g}$ & $3-\mathrm{O}_{2} \mathrm{NC}_{6} \mathrm{H}_{4}$ & $\left(\mathrm{CH}_{3}\right)_{2} \mathrm{CHCH}_{2}$ & 4 & 85 & 128 & $123-125^{38}$ \\
\hline $4 \mathrm{~h}$ & 4-OH-3-OMe- $\mathrm{C}_{6} \mathrm{H}_{3}$ & $\mathrm{CH}_{3}$ & 4 & 80 & $225-228$ & $231-232^{35}$ \\
\hline $4 \mathrm{i}$ & $4-\mathrm{OHC}_{6} \mathrm{H}_{4}$ & $\mathrm{CH}_{3} \mathrm{CH}_{2}$ & 4 & 82 & $200-202$ & $198-199^{36}$ \\
\hline $4 j$ & 2-Furyl & $\mathrm{CH}_{3}$ & 1 & 92 & 192 & $194-195^{33}$ \\
\hline $4 \mathrm{k}$ & 2-Furyl & $\mathrm{CH}_{3} \mathrm{CH}_{2}$ & 1 & 90 & $164-166$ & $166-168^{32}$ \\
\hline 41 & 2-Furyl & $\left(\mathrm{CH}_{3}\right)_{2} \mathrm{CHCH}_{2}$ & 1 & 88 & $112-114$ & - \\
\hline $4 \mathrm{~m}$ & $\mathrm{H}$ & $\mathrm{CH}_{3}$ & 1 & 90 & $202-204$ & $208-210^{32}$ \\
\hline $4 n$ & $\mathrm{H}$ & $\mathrm{CH}_{3} \mathrm{CH}_{2}$ & 1 & 84 & $168-170$ & $170-172^{32}$ \\
\hline 40 & $\mathrm{H}$ & $\left(\mathrm{CH}_{3}\right)_{2} \mathrm{CHCH}_{2}$ & 1 & 80 & $120-122$ & - \\
\hline
\end{tabular}

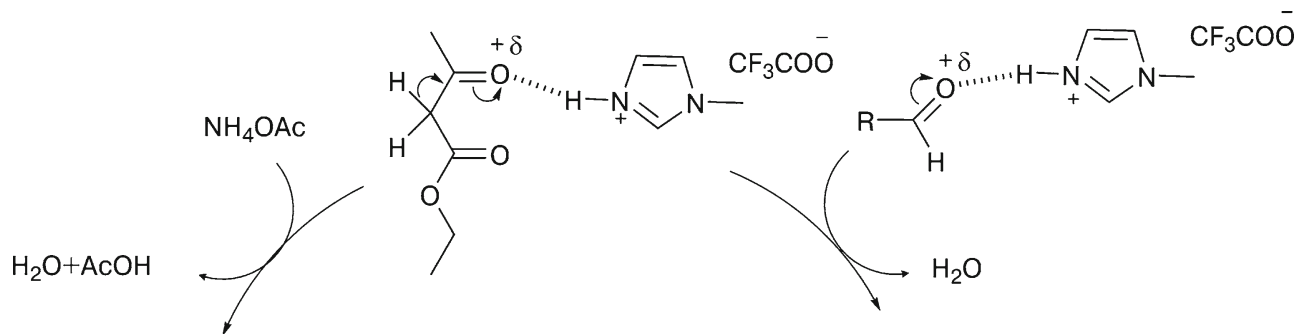<smiles>CCOC(=O)C=C(C)N</smiles><smiles>[R]C=C(C(C)=O)C(=O)OCC</smiles>

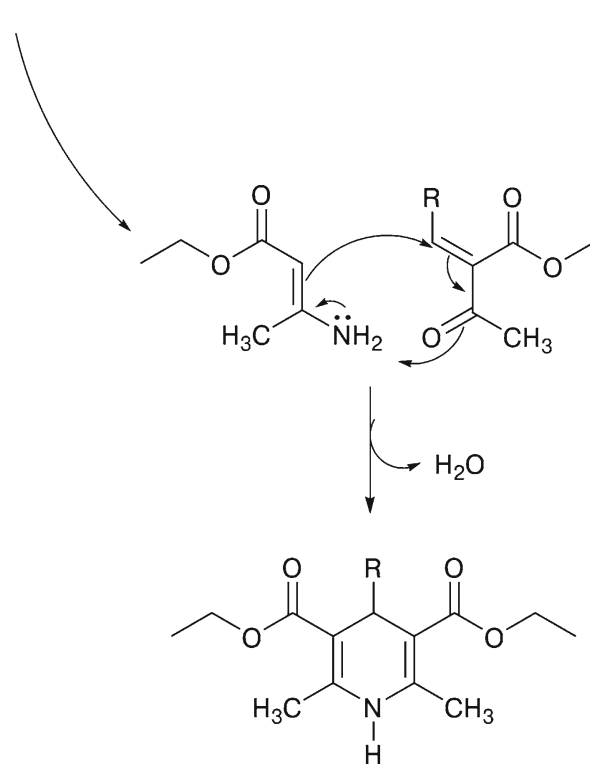

Scheme 2. Suggested mechanism for the synthesis of 1,4-DHPs in the presence of [Hmim]Tfa. 


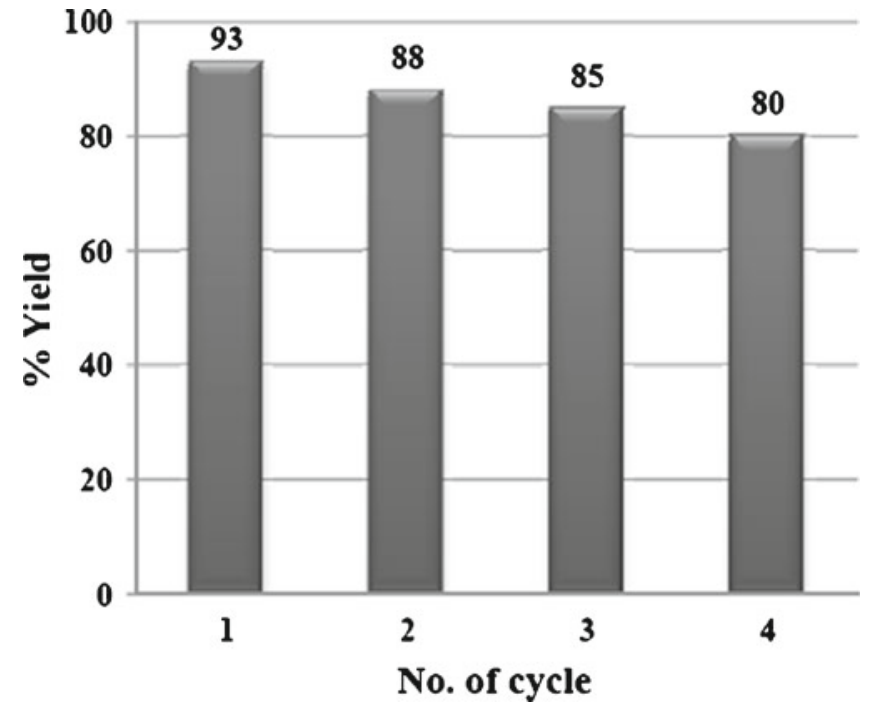

Figure 1. Recyclability study of ionic liquid on model reaction.

four times with remarkable retention in its activity (figure 1).

\section{Conclusion}

We have demonstrated the utility of [Hmim]Tfa in Hantzsch dihydropyridine reaction. This IL obviates the need for an additional catalyst and has allowed the preparation of a range of 1,4-DHPs in good to excellent yields (80-93\%). This procedure permits recycling of the IL with almost retention in activity. On the basis of these current efforts, it is likely that a number of organic reactions could be performed equally well or perhaps even more effectively using this ionic liquid. Studies to determine the applicability to other catalytic reactions are currently underway in our laboratory.

\section{Supporting information}

${ }^{1} \mathrm{H}$ NMR and ${ }^{13} \mathrm{C}$ NMR spectra of ionic liquid and some selected compounds are available as supporting information in the journal of Chemical Sciences Website (www.ias.ac.in/chemsci).

\section{Acknowledgements}

Authors thank Head, Department of Chemistry, Sardar Patel University for providing necessary research facilities. DKR is grateful to authorities of Sardar Patel University, Vallabh Vidyanagar for allocation of research funding in the form of seed grant-2011.

\section{References}

1. Polshettiwar V and Varma R S 2008 Acc. Chem. Res. 41 629

2. Santagada V, Perissutti E and Caliendo G 2002 Curr. Med. Chem. 91251

3. Kappe C O 2002 Curr. Opin. Chem. Biol. 6314

4. Cole A C, Jensen J L, Ntai I, Tran K L T, Weaver K J, Forbes D C and Davis Jr J H 2002 J. Am. Chem. Soc. 1245962

5. Ranu B C and Banerjee S 2005 Org. Lett. 73049

6. Wilkes J S 2004 J. Mol. Catal. A: Chem. 21411

7. Garuti L, Roberti M and Pizzirani D 2007 Mini-Rev. Med. Chem. 7481

8. Bossert F, Meyer H and Wehinger E 1981 Angew. Chem. Int. Ed. 20762

9. Shan R, Velazquez C and Knaus E E 2003 J. Med. Chem. 47254

10. R Abeles R H, Hutton R F and Westheimer F H 1957 J. Am. Chem. Soc. 79712

11. Mauzerall D and Westheimer F H 1955 J. Am. Chem. Soc. 772261

12. Triggle D J, Langs D A and Janis R A 1989 Med. Res. Rev. 9123

13. Hantzsch A 1882 Justus Liebigs Ann. Chem. 2151

14. Loev B and Snader K M 1965 J. Org. Chem. 301914

15. Cherkupally S R and Mekala R 2008 Chem. Pharm. Bull. 561002

16. Reddy C S and Raghu M 2008 Chin. Chem. Lett. 19775

17. Pasunooti K K, Nixon Jensen C, Chai H, Leow M L, Zhang D-W and Liu X-W 2010 J. Comb. Chem. 12577

18. Lei M, Ma L and Hu L H 2011 Synth. Commun. 411969

19. Wang L-M, Sheng J, Zhang L, Han J-W, Fan Z-Y, Tian H and Qian C-T 2005 Tetrahedron 611539

20. Debache A, Ghalem W, Boulcina R, Belfaitah A, Rhouati S and Carboni B 2009 Tetrahedron Lett. 50 5248

21. Ko S, Sastry M N V, Lin C and Yao C-F 2005 Tetrahedron Lett. 465771

22. Sabitha G, Reddy G S K K, Reddy C S and Yadav J S 2003 Tetrahedron Lett. 444129

23. Shaabani A, Rezayan A H, Rahmati A and Sharifi M 2006 Monatsh. Chem. 13777

24. Li M, Guo W-S, Wen L-R, Li Y-F and Yang H-Z 2006 J. Mol. Catal. A: Chem. 258133

25. Dadhania A N, Patel V K and Raval D K 2011 J. Braz. Chem. Soc. 22511

26. Dadhania A N, Patel V K and Raval D K 2012 C. R. Chim. 15378

27. Dabiri M, Baghbanzadeh M and Arzroomchilar E 2008 Catal. Commun. 9939

28. Crowhurst L, Mawdsley P R, Perez-Arlandis J M, Salter P A and Welton T 2003 Phys. Chem. Chem. Phys. 5 2790

29. Anderson J L, Ding J, Welton $\mathrm{T}$ and Armstrong D W 2002 J. Am. Chem. Soc. 12414247

30. Liu Q, Janssen M H A, van Rantwijk F and Sheldon R A 2005 Green Chem. 739

31. Suresh Kumar D and Sandhu J S 2009 Synth. Commun. 391957

32. Salehi H and Guo Q X 2004 Synth. Commun. 344349 
33. Sharma M, Agarwal N and Rawat D S 2008 J. Heterocycl. Chem. $\mathbf{4 5} 737$

34. Ghorbani-Choghamarani A, Zolfigol M A, Salehi P, Ghaemi E, Madrakian E, Nasr Isfahani $\mathrm{H}$ and Shahamirian M 2008 Acta Chim. Slov. 55644

35. Khadilkar B M, Jaisinghania H G, Saraf M N and Desai S K 2001 Indian J. Chem. B. 4082
36. Khadilkar B M, Gaikar V G and Chitnavis A A 1995 Tetrahedron Lett. 368083

37. Hernández-Gallegos Z, Lehmann F P A, Hong E, Posadas F and Hernández-Gallegos E 1995 Eur. J. Med. Chem. 30355

38. Akbari J D, Tala S D, Dhaduk M F and Joshi H S 2008 Arkivoc 126 